Société d'histoire de la révolution de 1848 et des révolutions du XIXe siècle

\title{
Justice, Politique et Franc-Maçonnerie sous la Troisième République : un conseiller à la Cour d'appel d'Angers, Victor Jeanvrot
}

\section{Vincent Bernaudeau}

\section{(2) OpenEdition}

Édition électronique

URL : https://journals.openedition.org/rh19/745

DOI : 10.4000/rh19.745

ISSN : $1777-5329$

Éditeur

La Société de 1848

Édition imprimée

Date de publication : 1 décembre 2003

Pagination : 201-226

ISSN : 1265-1354

\section{Référence électronique}

Vincent Bernaudeau, « Justice, Politique et Franc-Maçonnerie sous la Troisième République : un

conseiller à la Cour d'appel d'Angers, Victor Jeanvrot », Revue d'histoire du XIXe siècle [En ligne], 26/27 | 2003, mis en ligne le 19 février 2008, consulté le 28 février 2022. URL : http://

journals.openedition.org/rh19/745; DOI : https://doi.org/10.4000/rh19.745

Ce document a été généré automatiquement le 28 février 2022.

Tous droits réservés 


\title{
Justice, Politique et Franc- Maçonnerie sous la Troisième République : un conseiller à la Cour d'appel d'Angers, Victor Jeanvrot
}

\author{
Vincent Bernaudeau
}

Animé de sentiments républicains mûris dans une opposition à son milieu d'origine et ancrés dans le rejet d'un Second Empire finissant, Louis-Félix-Victor Jeanvrot resta toujours fidèle aux convictions politiques qui l'avaient habité dès sa jeunesse. Ne refusant aucun combat pour être de ceux qui allaient enraciner le régime que la révolution du 4 septembre avait annoncé, il fut à la fois témoin et acteur de son temps. Ses prises de position au cœur de l'enceinte judiciaire comme dans l'espace public lui firent connaitre quelques heures de gloire mais aussi goûter aux tourments d'une carrière mouvementée. Choisissant de rompre avec le conformisme et la réserve du corps d'État auquel il appartenait, ce magistrat s'investit dans l'action militante pour mener des initiatives audacieuses et avant-gardistes en marge de la sphère politique. Inlassable artisan d'une refonte de la législation et des institutions, il fut le promoteur, en 1886, du premier Congrès de la Réforme judiciaire, et apporta sa contribution à la vitalité des débats qui agitaient les élites par la création d'une revue juridique qui devint le vecteur de ses idées radicales. Soldat de la République autant que serviteur de la loi, il fut aussi un franc-maçon très actif qui eut la charge d'importantes responsabilités au sein du Grand Orient de France. Mais l'Affaire des fiches dans laquelle il se trouva compromis en 1904 brisa sa carrière et vint mettre un terme à ses engagements polymorphes orientés vers la défense des idéaux laïcs et républicains. Son appartenance à des réseaux situés aux confluents des espaces politique, judiciaire ou maçonnique permet de revisiter les liens entre pouvoir et groupes professionnels sous la Troisième République, mais aussi d'appréhender les mouvements sous-jacents à la haute fonction publique et les dispositions radicales de certains de ses membres pour la modernisation de la justice. Et si les luttes menées par Jeanvrot sous couvert de son statut d'inamovible, donnent à saisir le rôle des fonctionnaires maçons au sein de 
l'appareil d'État pour la consolidation du régime, sa trajectoire sociale et son positionnement idéologique révèlent aussi l'ascension et les aspirations des « nouvelles couches $»$ au tournant du siècle ${ }^{1}$.

Les tribulations professionnelles d'un magistrat aux origines " révolutionnaires »

2 Issu d'une famille honorable mais de modeste aisance, Victor Jeanvrot était né le $1^{\mathrm{er}}$ février 1846 à Montreuil-sur-Mer, département du Pas-de-Calais. Son père exerçait alors la profession d'avoué auprès du tribunal d'arrondissement de la ville, tandis que sa mère, Louise-Victorine Boitel, était sans profession ${ }^{2}$. C'est dans un milieu aux convictions politiques conservatrices et où la pratique du culte catholique était respectée que fut élevé l'enfant. Inscrit d'abord au collège de sa ville natale, il parvint à décrocher son baccalauréat et le sésame en poche, partit pour Douai, ville voisine disposant d'une université réputée, afin de passer les examens de la Faculté de droit. Achevant d'y apprendre les langues anglaise et allemande, il y suivit un cursus honorable et, à la date du 15 mars 1869, obtint le titre de licencié. Dès le mois suivant il se fit admettre au stage d'avocat du barreau de la ville et c'est là que la révolution du 4 septembre vint cueillir le "fils de ses œuvres" en lui offrant un poste dans la magistrature.

3 Simple avocat stagiaire, Victor Jeanvrot « était déjà très connu dans le ressort de Douai comme entièrement acquis aux idées républicaines " ${ }^{3}$. A l'image de certains étudiants en droit nés au milieu du siècle et qui allaient épouser la République en entrant au barreau ${ }^{4}$, il « appartenait [...] à une opposition assez avancée et s'associait ouvertement à ses tendances et à ses manifestations ", écrivant notamment dans les journaux et les revues littéraires «sur les matières d'économie politique et y donna[n]t des preuves d'un certain talent " ${ }^{5}$. Ses débuts à la barre auraient donc pu être remarqués, mais la carrière d'avocat l'enchantait peu et, conscient de la difficulté de se faire une position dans cette profession ${ }^{6}$, il choisit rapidement de tourner ses vues vers l'exercice d'une fonction publique à laquelle sa formation et ses convictions le prédisposaient. Il sollicita ainsi son admission dans la magistrature coloniale et limita ses prétentions au poste de juge ou de simple substitut en Algérie ${ }^{7}$. Mais comme pour beaucoup de ses confères au militantisme politique confirmé, l'avènement du gouvernement de la Défense Nationale allait lui ouvrir largement les portes de la magistrature, en lui offrant un poste qui n'était pas celui d'un début de carrière ${ }^{8}$. Ce fut en effet sans aucune présentation de la part des chefs de la Cour de Douai, qu'il débuta comme substitut à Valenciennes, le $1^{\text {er }}$ octobre 1870 , avant même d'avoir accompli ses deux années de stage réglementaire 9 . Pour ainsi se faire « improviser substitut de $5^{\text {ème }}$ classe [...] alors qu'il n'avait pas dix huit mois de stage ${ }^{10}$, Jeanvrot avait su mettre à profit ses relations politiques avec des personnages devenus influents comme Masure, ancien rédacteur en chef du Progrès du Nord qui l'avait employé dans son journal et qui, depuis octobre 1870, occupait à Tours les fonctions de sous-directeur du personnel au Ministère de Gambetta ${ }^{11}$.

En arrivant à Valenciennes dans un poste d'avancement, Jeanvrot «était controversé par tout le monde et imposé à ceux dont il devait partager les travaux ${ }^{12}$. Comme nombre de ces novices qu'un décret gouvernemental avait envoyés dans un poste auquel rien ne les avait réellement préparés, il n'avait qu'une vague idée des convenances auxquelles on devait se conformer dans le monde judiciaire. Méconnaissant surtout les usages en vigueur chez les magistrats du Palais et la déférence que les supérieurs étaient en droit d'attendre des nouveaux venus, il «se 
rendit à son poste sans même faire visite ou laisser sa carte aux chefs de la Cour ${ }^{13}$. Soupçonné d'avoir peu de respect pour les manières des hommes du monde, il ne mit ensuite pas dans ses relations la circonspection et la réserve que commandait la gravité sévère de ses fonctions, et trop systématiquement «les allures des personnes qu'il fréquentait n'étaient pas de nature à le recommander " ${ }^{14}$. Accueilli avec froideur, le substitut qui avait l'inexpérience et la fougue de la jeunesse, ne rencontra jamais vraiment la sympathie de ses collègues du tribunal. Après les avertissements qu'on lui adressa, on lui sut certes gré des soins qu'il mit à tenir une conduite plus réservée et à s'acquitter avec plus de rigueur de ses devoirs de magistrat, mais il resta sans cesse suspecté en raison de son "origine révolutionnaire ${ }^{15}$. Il suscitait notamment les ressentiments de certains de ses collègues qui, déçus dans leur espoir d'avancement par cette nomination, le considéraient comme un ambitieux n'ayant trouvé là qu'une récompense pour de menus et récents services rendus à la presse républicaine. Dès lors, s'il remplissait ses fonctions à la satisfaction des magistrats et des justiciables, «beaucoup s'attend[aï]ent à le voir partir d'une résidence où il lui sera[it] toujours difficile de bien se tenir en face d'un procureur général qui l'a[vait] vu entrer dans son ressort par une voie aussi irrégulière ${ }^{16}$.

En raison de la défiance et des animosités qu'il avait suscitées autour de lui, et au vu des difficultés qu'il allait devoir rencontrer dans ses perspectives de carrière, les chefs de la Cour de Douai, qui reconnaissaient chez lui intelligence, instruction et habitudes laborieuses, s'accordèrent sur la nécessité de l'éloigner du ressort. Dans son propre intérêt comme dans celui de la magistrature locale tout entière, le changement de résidence était devenu inévitable et un avis fut émis pour qu'à cette occasion il n'en subisse aucune disgrâce ${ }^{17}$. Les services du personnel de la Chancellerie n'en jugèrent pourtant pas ainsi et, se rangeant aux arguments du seul procureur général, envoyèrent Jeanvrot à Ajaccio comme substitut. Dans les milieux judiciaires de cette ville, la nouvelle de sa nomination puis son installation furent bientôt commentées de manière désobligeante ${ }^{18}$ et le nouveau parquetier ne tarda pas à « se considérer comme disgracié, [.... exilé ${ }^{19}$. Le sentiment profond d'avoir été sacrifié sur l'autel de considérations personnelles et politiques, comme la réalité subie du déracinement géographique et de l'isolement affectif, propres à beaucoup de magistrats mutés hors du continent, suscitèrent même aussitôt chez Jeanvrot dégoût, découragement et mauvaise volonté professionnelle. Ainsi, «sous prétexte qu'il ne sa[ve]it pas l'idiome corse, généralement parlé dans l'enceinte même des tribunaux, [il] rest[ait] absolument étranger aux débats correctionnels, quand il [était] à l'audience, et n'y développ[ait] jamais ses réquisitions. Au parquet, il ne reç[eva]it pas les justiciables qu'il ne compren[ait] pas. Il n'a[vait] donc à s'occuper que de la correspondance ou des travaux intérieurs ${ }^{20}$.

6 Dans cette affectation, relégué à des activités d'écriture souvent peu exaltantes et invité très occasionnellement à l'examen d'importants points de procédure, Jeanvrot ne put donc faire la preuve de ses capacités ni donner la mesure de son talent auprès de ses supérieurs hiérarchiques. Certes intelligent et étudiant le droit dès qu'un dossier lui en offrait la possibilité, le substitut montrait dans ses taches quotidiennes plus de "lassitude » qu'il ne laissait entrevoir d'" esprit d'initiative " ${ }^{21}$. La notation de ses chefs s'en ressentait de plus en plus et son maintien dans le poste n'avait d'ailleurs pu se réaliser que grâce à l'appui influent d'un vieil ami de son père, le député du Nord Hamille, auprès du premier président de la Cour de Bastia ${ }^{22}$. Il était devenu patent pour le chef du parquet qu'il devait être «le plus promptement possible rappelé sur le 
continent et placé sous la direction d'un procureur de la République très ferme qui lui apprendra[it] les choses élémentaires et qui le pliera[it] aux exigences quotidiennes du parquet ${ }^{23}$. Aussi, après avoir réclamé sans succès son avancement sur l'île, ses protecteurs du Nord comprirent qu'il fallait donc plutôt tenter de lui faire obtenir un poste en France ou en Algérie ${ }^{24}$. Aucun d'eux ne fut immédiatement entendu et l'intéressé, lui-même désireux de mettre fin à un épisode professionnel corse qui n'avait que trop duré ${ }^{25}$, dut se résigner à ces fonctions subalternes jusqu'en février 1877. Le substitut Jeanvrot n'avait donc pas encore su faire oublier ses origines, et l'« irrégularité d'affectation due à ses protecteurs d'alors " ${ }^{26}$ qui continuait à entacher son dossier allait même le contraindre à quelques pérégrinations judiciaires sous la République conservatrice. Ainsi, la Chancellerie l'envoya en février 1877 comme substitut dans la résidence de Prades, dans celle d'Hazebrouck en avril, de Béthune en septembre, et enfin de Dunkerque en février 1879. Et ce ne fut qu'au terme de huit années et demie de carrière dans ces fonctions peu rémunératrices et peu prestigieuses que, grâce aux inlassables recommandations des députés et sénateurs de sa région d'origine, Jeanvrot put enfin obtenir la direction d'un parquet avec sa nomination à Baugé le 19 juin 1879. Son parcours avait certes été linéaire au sein du ministère public, mais particulièrement lent et difficile pour ce soldat de la République dont l'«avancement [avait été] retardé parce que nommé au 4 septembre, [...] les gouvernements réactionnaires qui [s'étaient] succédés [lui avait] fait expier cette origine ${ }^{27}$.

7 À son arrivée dans le ressort d'Angers, la République venait de triompher mais la terre sur laquelle Jeanvrot s'installait demeurait fidèle aux idées conservatrices ${ }^{28}$. Les députés comme les notables composant les assemblées locales voulaient en découdre avec le nouveau régime et certaines dynasties familiales qui en étaient issues accaparaient encore largement la fonction publique. Aussi, l'annonce de sa nomination dans ce département réactionnaire fut-elle ressentie par le procureur général investi en 1879 comme une " une véritable bénédiction » ${ }^{29}$, à l'heure où l'épuration réclamait des nouveaux parquetiers un indéfectible soutien. Aussitôt installé dans sa nouvelle résidence de Baugé, Jeanvrot montra du reste qu'il était doué de beaucoup de fermeté, qu'il disposait d'habitudes d'ordre et de véritables qualités d'organisation. D'une austérité de mœurs et d'une rigueur morale propres à susciter la satisfaction de ses chefs, il était en outre doté d'une parole élégante et développait un style aisé qui lui firent connaître quelques succès d'audience, notamment lors de l'exécution des décrets anti-congréganistes promulgués en mars $1880^{30}$. Le rôle qu'il tint à son poste autant que les écrits qu'il fit publier à cette occasion, révélèrent à ses supérieurs l'ampleur de son talent et lui permirent, sur l'initiative du procureur général, d'accéder à un rapide avancement. Ce dernier considéra qu'après bientôt dix années de services judiciaires et de dévouement à la cause républicaine, qui jusque-là avaient plutôt constitué pour lui " une entrave à son avancement, [...] le moment paraî[ssai]t arrivé de lui donner un poste en rapport avec ses services et sa capacité ${ }^{31}$. N'ayant jamais varié dans ses opinions politiques, même aux moments les plus difficiles de sa carrière, s'étant toujours très nettement engagé et n'ayant jamais marchandé son concours au gouvernement, le chef du parquet général estimait que les atouts professionnels et surtout politiques du procureur de Baugé étaient de nature à rendre son concours très utile au sein d'une Cour. Et pour mieux satisfaire les souhaits de son subordonné, il avait alors engagé quelques tractations en sa faveur avec son collègue d'Amiens afin de le rapprocher du Pas-de-Calais dont il était originaire. Mais avant même qu'il ne puisse 
le proposer pour un poste d'avancement, un décret daté du 30 juin 1880 vint nommer Jeanvrot aux fonctions de substitut à la Cour d'Angers.

8 Après s'être félicité de la conduite irréprochable qu'il avait tenu dans son arrondissement sous les cabinets Waddington et Freycinet, ses supérieurs hiérarchiques eurent tôt fait de le distinguer parmi ses collègues. Presque un an après son entrée au parquet général, un rapport lui valait en effet des éloges unanimes concernant son activité, son zèle, son style ou encore son érudition ${ }^{32}$. Mais si de par son expérience antérieure il avait su se rendre propre au service des audiences civiles et correctionnelles, montrer qu'il entendait bien la police judiciaire et être bon administrateur, rapidement Jeanvrot parut également mal disposé pour devenir un parquetier hors norme. Aux dires de sa hiérarchie, dans ce poste actif de substitut du procureur général, «la gène qu'il éprouv[ait], annul[ait] en quelque sorte sa valeur personnelle et [...] quoiqu'il s'exprim[ât] d'une façon très correcte et avec une certaine facilité, on sent[ait] que ses moyens [étaient] en grande partie paralysés par la crainte ${ }^{33}$. Les qualités qu'il avait pu déployer dans son petit tribunal de $3^{\text {è classe }}$ semblaient ne plus suffire dans les fonctions très exposées de la Cour. Le maniement du verbe dont il faisait preuve à l'audience paraissait ne pas emporter la conviction de ses pairs et la force de ses convictions républicaines ne pouvait le disputer à une extériorité qui lui ôtait quelque autorité dans ses réquisitoires ${ }^{34}$. Aussi, la place de Jeanvrot était-elle plutôt marquée dans la magistrature assise où, selon ses supérieurs, ses qualités personnelles et professionnelles semblaient plus à même désormais de pouvoir s'épanouir. Pressentant qu'il ne pourrait pas obtenir l'avancement escompté dans le ressort, en raison de l'ancienneté de deux de ses collègues, lui-même avait marqué son intention de quitter l'Ouest et exprimé dès 1881 son désir d'abandonner le ministère public pour le calme du siège. Le procureur général, qui reconnaissait l'extrême timidité de son "précieux collaborateur» comme un obstacle majeur à l'exercice des fonctions d'avocat général, avait donc accepté « avec grands regrets » la perspective de se séparer de cet «excellent magistrat [...] entièrement dévoué à la cause républicaine ${ }^{35}$ et s'était résolu à faciliter sa nomination comme conseiller dans un ressort proche de sa région d'origine ${ }^{36}$. Mais le 17 avril 1883, quelques mois seulement avant que l'épuration la plus massive de l'histoire judiciaire française n'extirpe de la compagnie angevine les éléments hostiles à la République, Jeanvrot obtint d'être nommé conseiller sur place ${ }^{37}$.

Le chassé-croisé engendré par cette «révolution judiciaire» avait permis un renouvellement quasi complet de la magistrature inamovible et Jeanvrot y apparut bientôt comme le plus expérimenté et l'un des membres les plus éminents. Présidant « d'une manière remarquable les assises du ressort d'Angers de 1883 à 1885 " ${ }^{38}$, il fit en effet preuve dans ses nouvelles fonctions d'un jugement sûr et droit, d'une science approfondie, au point que ces qualités jointes à « la maturité de son esprit, f[iren]t de lui un magistrat d'une valeur exceptionnelle ${ }^{39}$. Totalement dévoué à ses fonctions, toujours prompt à fournir un labeur opiniâtre et maîtrisant parfaitement les questions juridiques les plus épineuses, le conseiller avait des «connaissances étendues [qui] donn[ai]ent à ses opinions une grande autorité dans les délibérations de la Cour " ${ }^{40}$. En outre, «le gouvernement ne p[ouvai]t faire choix d'un républicain plus fervent et plus éclairé » ${ }^{41}$ pour un poste d'avancement tel que celui de président de chambre, qu'on réclamait pour lui avec insistance depuis $1900^{42}$. Mais dans un corps judiciaire où les promotions étaient commandées par un système discrétionnaire et où plus on gravissait la hiérarchie, plus le conformisme politique était de rigueur ${ }^{43}$, l'excellence 
professionnelle de Jeanvrot avait été ternie par ses initiatives extra-judiciaires. Oublieux de son devoir de réserve, il avait fait de son indépendance un marchepied à ses ambitions et, depuis son arrivée dans le Maine-et-Loire, s'était impliqué dans des querelles locales qui lui avaient valu les foudres réactionnaires comme la critique de républicains opportunistes influents ${ }^{44}$. Tout en ne tarissant pas d'éloges sur les compétences du conseiller, les chefs de la Cour s'étaient montrés soucieux de l'image de la compagnie auprès des notabilités et de la Chancellerie, et avaient constamment refusé de le présenter pour cet avancement. Ils avaient craint que la promotion sur place ne lui offre l'occasion de conforter son attitude radicale et que la consécration professionnelle, le surcroît de prestige social et d'autorité qu'il était susceptible d'en retirer ne lui suscitent des animosités plus vives encore dans l'opinion publique, ce qui put être préjudiciable à l'ensemble du corps judiciaire ${ }^{45}$. Les influentes relations de Jeanvrot n'avaient pu compenser son défaut de discrétion dans l'accomplissement de ses devoirs extérieurs et l'indéniable qualité des travaux d'érudition qu'il avait multipliés en arrivant dans le ressort, sa parfaite connaissance des affaires comme sa qualité de doyen de la Cour, à partir de 1900, n'avaient pas suffit à lui assurer le bel avancement que pourtant lui promettaient les services rendus à la cause républicaine.

Un réformateur au service de l'État, de la justice et de la République.

Dès la fin de ses études, Jeanvrot avait tenté une courte expérience journalistique et littéraire, et son goût du travail comme ses heureuses dispositions pour discuter des sujets les plus divers en droit, économie politique ou philosophie s'étaient alors manifestés. Servi par des connaissances étendues et une grande curiosité d'esprit, il avait ensuite déployé ses talents à son entrée dans la magistrature en se signalant au procureur général de la Cour de Bastia comme un substitut très studieux qui, pour occuper ses loisirs dans une île où il n'avait aucune relation et ne cherchait pas à s'en créer, étudiait le droit en préparant un traité sur les assurances ${ }^{46}$. Célibataire et "peu disposé à se marier ", durant toute sa carrière Victor Jeanvrot mena aux dires de ses supérieurs, une existence solitaire et borna ses relations aux «visites strictement nécessaires ${ }^{47}$. Vivant honorablement grâce à une fortune qui le rendait indépendant ${ }^{48}$, toujours il resta entouré de la respectabilité sociale que la magistrature exigeait de ses membres. Avec son arrivée dans le ressort d'Angers en 1879, son activité intellectuelle connut un tournant puisqu'il choisit alors de se consacrer pleinement à de nombreuses occupations extra-judiciaires et que l'accélération de ses productions coïncida aussitôt avec des succès d'édition remarqués. Désireux de se signaler à ses chefs et aux ministres par son activité hors du Palais ${ }^{49}$, il multiplia alors les recherches théoriques en travaillant « sans relâche » ${ }^{50}$ pour l'amélioration de l'organisation et des procédures judiciaires. S'il ne dédaigna pas aborder quelquefois les questions historiques ${ }^{51}$, la philosophie ou les idées politiques ${ }^{52}$, ce fut en effet par ses travaux strictement juridiques qu'au cours de sa carrière angevine il s'assura une solide réputation ${ }^{53}$. Versé dans l'étude des points de jurisprudence comme dans l'examen des questions pratiques, il fit paraître dès 1880 un traité-formulaire particulièrement apprécié des fonctionnaires de l'ordre administratif ${ }^{54}$ ainsi qu'un "excellent livre résumant dans une forme très heureuse toute la discussion juridique concernant les décrets de mars $»{ }^{55}$, dans lequel il su judicieusement ajouter de nouveaux arguments en faveur de leur légitimité et des droits de l'État. «Fort consulté[e] par les magistrats du parquet et les fonctionnaires dans l'accomplissement de leur mission ${ }^{56}$, cette parution eut deux éditions et fut tirée à 1500 exemplaires. C'était là un premier grand succès dont le procureur de Baugé allait être récompensé par un avancement 
considérable à la Cour, mais déjà il était attelé « à la refonte et publication des œuvres de Merlin de Douai - répertoire et questions de droit - sous forme de commentaire du Code civil ${ }^{57}$. Et dès l'année suivante, en dépit de ses nouvelles et importantes fonctions de substitut du procureur général, il faisait paraître une Étude sur les progrès de la procédure criminelle en France, qui allait être de nouveau remarquée dans les milieux judiciaires.

11 "Travailleur infatigable aimant passionnément l'étude " ${ }^{58}$, Jeanvrot maintenait parallèlement une collaboration très active avec diverses publications juridiques comme La Loi, le Bulletin de la Société de législation comparée ou la Revue critique de législation et de jurisprudence. Et bien qu'il eût également à diriger pendant quelque temps la Revue des lois. Recueil périodique des lois et décrets ainsi que La jurisprudence pratique. Recueil périodique des décisions judiciaires, il s'attacha invariablement à poursuivre son œuvre personnelle. Appuyant autant sa réflexion sur des expériences de prétoires que sur une large documentation juridique et historique, il fit éditer successivement plusieurs ouvrages ayant trait aux institutions ou au personnel judiciaire. La question du serment parut en $1882 \mathrm{chez}$ Chevalier-Marescq, Les juges de paix élus sous la Révolution. Notes et documents inédits, chez Charavay l'année suivante, tout comme La Magistrature ${ }^{59}$, ouvrage en deux volumes dans lesquels il traduisait son impatience de réformes radicales concernant l'inamovibilité, le nombre de postes, les conditions de capacité ou le mode de désignation des juges ${ }^{60}$. Devenu conseiller à la Cour, une expérience distinguée à la tête des assises du ressort lui autorisa aussi la composition et la publication chez l'éditeur Pichon, d'un Mémento d'audience du Président d'assises qui connut dès 1884 un vif succès avec deux éditions.

Pour ses supérieurs angevins comme pour le Garde des Sceaux, à la bienveillance duquel il avait été maintes fois signalé pour un avancement, il était assurément « un érudit dans la meilleure acception du mot, un véritable savant ${ }^{61}$. Ses capacités d'analyse, ses dispositions pour la discussion des points de droit et la restitution d'une argumentation toujours solide étaient telles que certains de ses protecteurs avaient d'ailleurs tenté, dès 1881 , de lui faire obtenir un poste dans les bureaux de la Chancellerie. Le procureur général souhaitant lui-même le voir attaché à la direction des affaires civiles ou à celle des affaires criminelles, avait souligné combien il était susceptible d'y rendre d'éminents services par son singulier amour du travail et des recherches ou par ses habitudes de classements méthodiques si précieuses dans l'intérieur d'une grande administration ${ }^{62}$. Jamais pourtant, en dépit de ces rapports élogieux sur son érudition peu commune et ses incontestables capacités, Jeanvrot ne put se rapprocher de « Paris où l'appel[aient] assez souvent les recherches auxquelles il se livr[ait] et les soins à donner à la publication de ses nombreux travaux " ${ }^{63}$. Mais le "jurisconsulte distingué, [le] travailleur émérite » ${ }^{64}$ qu'il était ne renonça pas pour autant à apporter sa contribution aux débats qui agitaient l'opinion. Encouragé par le succès rencontré au sein des élites judiciaires et politiques ${ }^{65}$, assuré d'être désormais compris parmi les plus savants observateurs des questions juridiques, il poursuivit la publication de ses travaux ${ }^{66}$ et afficha plus ouvertement encore son ambition d'être à l'avant-garde d'un renouveau législatif.

13 Toujours soucieux d'acquérir un surcroît de légitimité, il ne put résister aux sirènes puissantes d'une reconnaissance professionnelle et politique qui pouvait être un accélérateur pour une carrière au point mort depuis 1883 , et voulut se poser comme un acteur majeur de la refonte du système judiciaire français. En 1885, le franc-maçon 
Jeanvrot créa et prit la direction de la Revue de la réforme judiciaire. S'assurant dans un premier temps la collaboration de magistrats et de jurisconsultes éminents comme Jousserandot, Guérin de la Grasserie, Mazeau, Eyssautier, Fabreguette ou encore Pally, il affirmait là son souci d'instaurer un espace de réflexion et un lieu de propositions des réformes à entreprendre. Dans la "nébuleuse réformatrice " ${ }^{67}$, la revue était en effet une tribune ouverte aux discussions contradictoires et aux opinions sérieuses où l'investissement de chacun devait venir renforcer les liens et structurer les réseaux de tous. Elle constituait un lieu de valorisation du capital professionnel et d'expression d'une recherche de promotion sociale, mais permettait aussi à Jeanvrot et ses amis d'investir à la fois un lieu de sociabilité et un espace symbolique. Toutefois, la fédération de ces volontés maçonniques ou profanes était moins décidée à accompagner le mouvement réformateur que résolue à inspirer en France une refonte profonde de la législation et des institutions demeurées immuables depuis le début du siècle. L'objectif que le fondateur se proposait d'atteindre au premier chef était en effet la reconnaissance d'un puissant pôle au sein du monde judiciaire, capable d'être l'interlocuteur privilégié du pouvoir ${ }^{68}$.

14 Tout en étant un instrument propre à susciter la discussion juridique et à confronter les points de vue sur les progrès à apporter au système judiciaire français, la revue n'en devait pas moins constituer un organe de propagande destiné, selon Jeanvrot, à la mise en œuvre de projets à la fois techniques et politiques ${ }^{69}$. Si dans certaines sociétés, associations ou loges, quelques-uns mûrissaient les questions économiques ou sociales qui préoccupaient les esprits de cette fin de siècle, lui et ses collaborateurs dénonçaient "le rite incantatoire d'une réforme de la justice sans cesse annoncée et sans cesse ajournée ${ }^{70}$ et s'appliquaient à offrir les moyens matériels et intellectuels qui pouvaient amener à une refonte rapide des Codes et des structures judiciaires. Comme eux, Jeanvrot était animé d'idées radicales et les propositions formulées ne manquaient donc pas de témoigner d'une certaine audace et d'une volonté de rupture avec les pratiques du passé. En particulier, il restait convaincu que le gouvernement républicain devait d'abord réaliser ses principes dans les institutions et que la réforme judiciaire se devait d'être démocratique puisque le nouveau régime avait pour base la souveraineté populaire. Aussi proposait-il la suppression de l'inamovibilité, l'élection des juges et des parquetiers, la réduction des tribunaux, l'élargissement des compétences des juges de paix ou encore la création d'assises correctionnelles. «Bien que d'apparence timide, [...] Jeanvrot a[vait] des idées arrêtées et une grande force de volonté » ${ }^{71}$, et il n'hésita d'ailleurs pas, sous couvert de sa triple position de magistrat, de savant et de francmaçon, à rompre rapidement avec le relatif isolement de l'espace associatif dans lequel il s'était impliqué jusqu'alors pour élargir sa sphère d'influence. Choisissant d'investir le champ politique, tout en restant en marge du pouvoir, il organisa en effet dès 1886 à son domicile angevin, des conférences associant juristes et parlementaires afin de discuter quelques questions juridiques importantes soulevées par la presse ou les Chambres.

15 Apprenant qu'avait ainsi lieu à Angers le premier Congrès de la réforme judiciaire et que la presse républicaine de tendance radicale s'en faisait largement l'écho ${ }^{72}$, la Chancellerie enjoignit au premier président de la Cour de lui adresser un rapport circonstancié. Dans ce dernier, transparaissait alors, sinon l'expression explicite de la résistance judiciaire au mouvement réformateur fin de siècle, au moins une défiance à peine voilée envers la surenchère radicale de Jeanvrot. Dans un corps où l'une des vertus cardinales était de cultiver une certaine distance envers les affaires du monde, le 
premier président ne pouvait couvrir l'entreprise de dénigrement qu'avait initié son subordonné et qui menaçait à la fois de ruiner son autorité de magistrat et de nuire à la respectabilité de la compagnie. Il y fustigeait le projet de Jeanvrot en raison de la position que ce dernier occupait au sein de la Cour ${ }^{73}$, des personnalités judiciaires angevines qui s'y étaient associées ${ }^{74}$ et des innovations hardies qui ne manqueraient pas d'y être discutées. Et surtout, il redoutait que la presse réactionnaire ne prenne prétexte de l'événement pour se déchaîner contre la magistrature républicaine investie depuis la loi de $1883^{75}$. D'autant que les réunions projetées promettaient de connaître un vif succès et, comme le soulignait le procureur général, d'avoir un retentissement au-delà du seul ressort d'Angers en raison de la publicité qui serait faite autour des hommes politiques conviés ${ }^{76}$. Les réticences des chefs de la Cour étaient donc explicitement rapportées, mais « dans la crainte de faire naître un incident [...] peut être de nature à créer des difficultés à [la] Chancellerie, à raison des personnalités mises en jeu, de M.M. Floquet et Colfavru » ${ }^{77}$, ces derniers avaient cru judicieux de ne pas contrecarrer l'initiative frondeuse du conseiller et conclu finalement à la seule surveillance du congrès.

16 L'assemblée se réunie donc par deux fois, les 13 et 14 juin 1886, sous la présidence d'honneur de M. Floquet, président de la Chambre des députés et sous la présidence effective du député Colfavru, maçon comme Jeanvrot et la plupart des autres participants. Un projet de règlement comportant plus de 200 articles fut adopté, portant d'abord en principe que la Société de la Réforme judiciaire créée à l'occasion, était une association exclusivement scientifique, ayant un caractère purement juridique et spéculatif. Mais derrière la volonté affichée des participants de donner à leur initiative la marque d'un engagement apolitique, le dessein apparu dans la teneur des séances ne pouvait masquer un mode d'exercice de l'action politique. Le programme établi soulignait en effet l'ambition de favoriser le vote à la Chambre de textes résolument progressistes visant au remodelage complet de l'organisation judiciaire. Au cours des discussions, l'assemblée qui s'était emparée des questions brûlantes relatives aux juridictions de paix, n'hésita notamment pas à critiquer ouvertement l'article $1^{\mathrm{er}} \mathrm{du}$ projet de loi soumis à la Chambre ${ }^{78}$. Elle demanda qu'on rehausse les traitements des magistrats cantonaux, émit également le vœu de voir appliquer le jury à cette juridiction et nomma deux commissions chargées, l'une d'étudier la question de la réorganisation des fonctions d'avocat et d'avoué, l'autre, de procéder à la révision du livre premier du Code de procédure concernant les justices de paix. Résolue à approfondir ses débats et à constater des suites parlementaires données à cette première initiative, elle décida enfin qu'une seconde réunion devrait être rapidement organisée ${ }^{79}$.

17 Par la création d'une revue et la publicité faite autour de ses activités, Jeanvrot avait donc su valoriser son savoir d'expert dans un espace associatif et promouvoir ses idées. Mais s'il avait déjà pris une part considérable aux débats juridiques de son temps par ses écrits, l'organisation du premier Congrès de la réforme judiciaire lui avait permis de dévoiler la mesure de son ambition, de son talent et d'apporter la preuve de sa force de convictions. L'impulsion qu'il avait donnée aux réunions de juin 1886 par la fédération d'hommes déterminés venus de la sphère judiciaire et d'horizons politiques, avait marqué assurément la contribution décisive du conseiller angevin au grand mouvement réformateur des années 1880 . Au-delà du renforcement de la densité des réseaux personnels ou professionnels de chacun, cet investissement dans l'espace public était venu témoigner des interconnaissances politico-judiciaires et de leur poids 
grandissant dans la préparation des travaux législatifs. Surtout, il avait révélé que la magistrature, loin d'être un corps monolithique, était de plus en plus ouvertement tiraillée entre les partisans silencieux des traditions et les artisans convaincus par les nécessités d'une modernisation de la justice. Et ce vaste mouvement qui était aussi consécutif des bouleversements intervenus dans le personnel depuis 1879, participait de la quête de légitimité des magistrats républicains ${ }^{80}$ et du renouvellement plus global engagé au sein des élites de l'État ${ }^{81}$.

En réclamant que le personnel judiciaire soit soustrait du rapport de dépendance dans lequel l'avait contenu le pouvoir politique et que ses rangs s'ouvrent enfin socialement par un recrutement démocratique qui eût balayé toutes les pratiques discrétionnaires, Jeanvrot avait affiché sa volonté de rupture avec la modération des projets opportunistes. Mais il avait aussi adopté une attitude qui devait par trop dénoter au sein d'une Cour nouvellement recomposée. Sa hiérarchie, soucieuse de confiner ses subordonnés dans la stricte sphère de leurs attributions et de signifier à la Chancellerie qu'elle exerçait un contrôle exact de ses collaborateurs, l'avait mis à l'index en dépit de ses indéniables compétences professionnelles. Par ce biais, elle avait à la fois espéré pouvoir faire oublier les débordements d'indépendance de la magistrature prérépublicaine contre le régime, et limiter l'implication du conseiller dans les débats qui s'agitaient sur le terrain politique et qui pouvaient être préjudiciables à l'image de la compagnie. Mais l'intransigeance radicale de Jeanvrot, qui accusait de ces rapports de force traversant la société judiciaire républicaine, allait devoir s'afficher plus nettement encore dans les querelles locales ou le scandale des fiches, et mêler jusqu'auboutisme à compromission.

L'Affaire des fiches : entre engagement maçonnique et combat politique.

Ce fut dans la tenue du 11 février 1884 que la Loge Travail et Perfection, à l'Orient d'Angers, procéda à l'initiation au grade d'apprenti du conseiller Jeanvrot ${ }^{82}$. Or dans ce pays angevin où l'Église était puissante, la population toujours sous l'emprise des notables locaux et l'administration encore peuplée par les héritiers des anciennes élites, la République était farouchement combattue et ses partisans rudement pris à partie par les rédacteurs des organes de presse réactionnaires ${ }^{83}$. Parmi eux l'on retrouvait d'anciens magistrats révoqués en 1883 dont l'hostilité était particulièrement vive et l'emprise sur le lectorat forte ${ }^{84}$. Jamais ils ne manquaient une occasion de dénoncer dans leurs colonnes le péril maçonnique en stigmatisant les frères qui, au sein d'une magistrature renouvelée, servaient les nouveaux gouvernants. Et l'imagination d'une opinion publique toujours prompte à se laisser convaincre du complot organisé par la secte des "trois points", se nourrissait des violentes campagnes qu'ils orchestraient ${ }^{85}$. Aussi, l'initiation du conseiller ne manqua pas d'échauffer les esprits et de faire naître une polémique après que ce dernier ait, contre l'avis de sa hiérarchie, répliqué aux attaques dans le très républicain Patriote de l'Ouest ${ }^{86}$. Il y avait d'abord argué que sa conscience de magistrat, l'indépendance et l'impartialité absolues que lui imposaient les devoirs de sa position ne pouvaient en rien être entravées par le serment qu'il venait de prêter ${ }^{87}$. Et surtout, il y avait dénoncé l'hypocrisie de ses détracteurs, victimes judiciaires de l'épuration de 1883 qu'il tenait pour des nostalgiques des régimes autoritaires et d'une magistrature aux ordres ayant elle-même compté une quinzaine d'affiliés à la loge maçonnique angevine. Certes, la carrière de Jeanvrot n'allait avoir à subir aucune retombée immédiate de cette agitation journalistique, mais l'incident avait fait grand bruit au sein des élites du département et l'émotion avait été particulièrement perceptible dans les milieux 
judiciaires. L'exposition du conseiller au déchaînement des passions était venue en effet témoigner de l'opposition sourde que se livraient les juges républicains et l'ancienne magistrature, mais aussi raviver les tensions exacerbées entre catholiques et francsmaçons angevins depuis l'affaire des décrets de 1880 et confirmer qu'à travers son engagement, le glissement de la Maçonnerie vers un soutien sans faille au nouveau régime était opéré ${ }^{88}$.

Cette effervescence avait été d'autant plus entretenue que Victor Jeanvrot, admis au grade de Maître à la loge Travail et Perfection le 22 septembre $1884{ }^{89}$, allait rapidement conquérir une position privilégiée parmi la maçonnerie angevine. Choisi par ses frères pour devenir Orateur de la loge, il allait être également désigné par eux pour occuper les fonctions de Garant d'amitié ${ }^{00}$. Comme son collègue Chudeau, président de chambre à la Cour, qui correspondait avec la loge Thémis de Caen, Jeanvrot allait en effet établir des liens étroits et féconds avec les élus d'Occident de Basse-Terre, Les enfants de la Vérité de Tours, les frères de La Sincérité de Reims, ceux de La Persévérance de Saumur, de L'Aménité du Havre, de La Fidélité de Lille et enfin des loges La Sincérité, La Parfaite Union et Constante Amitié Réunies de Besançon ${ }^{91}$. Autant de relations fraternelles entretenues de longue date qui pouvaient lui assurer à la fois une situation enviée parmi les maçons ligériens, constituer un réseau d'appuis influents pour sa carrière judiciaire et lui servir de relais dans son combat politique. Cette situation au cœur de la Maçonnerie se trouva encore renforcée par les positions de responsabilité que Jeanvrot allait être amené à occuper au siège parisien du Grand Orient de France. Son statut de magistrat lui permit en effet d'être membre de la Chambre de cassation, sa position d'érudit et de littérateur distingué de compter parmi les membres de la Commission de la bibliothèque, mais surtout ses convictions profondes de rejoindre le cercle très fermé que constituait la Commission d'étude et de propagande. Pour faire triompher la République contre le conservatisme et prévaloir les idées laïques sur le cléricalisme, le Grand Orient s'était en effet doté en 1891 d'un comité spécial composé de ses membres les plus sûrs et les plus influents, capables de mener leurs frères au combat ${ }^{92}$. Et depuis lors, des tenues blanches aux conférences, de la presse maçonnique aux coopérations entre loges et cercles républicains, toute l'action des temples avait semblé contrôlée et orientée vers le terrain politique.

21 Certes, la Franc-Maçonnerie restait pour Jeanvrot et ses frères « une institution philanthropique, philosophique et progressive qui a(vait) pour objet la recherche de la vérité, l'étude de la morale et la pratique de la solidarité " ${ }^{93}$, mais depuis la crise du 16 mai et surtout l'épisode des décrets en 1880 , les frères s'étaient résolument unis pour opposer une digue aux défenseurs des doctrines de l'Église ${ }^{94}$. Tous considéraient la Maçonnerie comme une "sentinelle avancée du progrès humain " ${ }^{95}$ et ils aimaient à clamer que "ses enfants toujours [seraient] au premier rang, au poste de combat " ${ }^{96}$ pour que la démocratie l'emporte sur l'autocratie cléricale. Car dans cet Ouest réactionnaire, les loges angevines défendaient une conception de la Maçonnerie qui n'était plus seulement initiatique ou repliée sur la réflexion philosophique et symbolique, mais prônaient au contraire une intervention dans le champ politique, un engagement dans l'espace public prolongeant leurs réflexions sur les questions de société. Comme en témoignent les comptes rendus de leurs tenues, les procès-verbaux de leurs délibérations ou les discours de leurs membres, elles marquaient leur intérêt croissant pour les questions profanes (positivisme, suffrage universel, réforme de l'instruction, rôle des femmes, question coloniale) et leur prédilection pour des sujets comme les rapports entre l'Église et l'État, le cléricalisme ou la mise en pratique des 
principes de 1789. A cette maçonnerie combative, «à ses laborieux et patriotiques efforts, rev[enai]t tout l'honneur de la mise en œuvre révolutionnaire " et selon Jeanvrot, les frères devaient sortir des temples pour se signaler par la fermeté de leurs principes face à la cohorte des jésuites, « ces implacables ennemis » du régime ${ }^{97}$.

Comme ses coreligionnaires du ressort, très tôt le rationaliste Jeanvrot s'était donc impliqué dans les luttes locales et avait su afficher ses convictions pour être en première ligne dans ce combat ${ }^{98}$. Fort de ses succès personnels et professionnels, mais aussi de l'envergure maçonnique acquise, il s'était même laissé gagner peu à peu par "la maladie radicale [qui] [étai]t l'amour de la réclame " ${ }^{99}$, en cherchant à s'imposer à l'opinion républicaine opportuniste et à quelques-uns de ses représentants les plus officiels. Ainsi, lors de la tenue du 29 décembre 1885, il «av[ait] pris la parole pour signaler en termes forts acerbes [...] l'attitude de M. le préfet de Maine-et-Loire [...] et demander que celui-ci fut dénoncé au Grand Orient " pour la modération de son républicanisme ${ }^{100}$. D'une intransigeance grandissante, il avait aussi été l'instigateur au cours de l'année 1896, d'un conflit interne à la loge Travail et Perfection d'Angers qui avait amené de nombreux frères, en désaccord profond avec ses méthodes autoritaires et des dispositions hostiles aux libres-penseurs, à menacer de démission ${ }^{101}$. Dans ce climat délétère de surenchères, il était alors allé jusqu'à officialiser la rupture entre maçons angevins, en constituant une nouvelle loge au chef-lieu du département, qui reprit le nom d'une de ses devancières, disparue en 1814, Le Tendre Accueil, et s'installa le 14 mars 1897 avec une soixantaine de membres. La scission maçonnique qu'il avait ainsi suscitée allait d'ailleurs devoir perdurer au-delà des tentatives de fusion entre ateliers évoquées en novembre $1903^{102}$.

23 En ce début de siècle pourtant, de nouvelles préoccupations allaient permettre aux républicains et aux francs-maçons angevins de reconstruire un semblant d'unité. Après que l'épisode boulangiste et les soubresauts de l'Affaire Dreyfus aient révélé une crise profonde dans le pays, les votes successifs des lois de 1901, 1902 et 1904 sur les associations et l'enseignement, allaient en effet raviver les passions religieuses et faire craindre un danger pour le régime ${ }^{103}$. Menaçant d'une violente réaction, les cléricaux et les nationalistes précipitèrent alors le regroupement des forces progressistes et les maçons d'Angers, d'accord avec le directeur du journal Le Patriote, choisirent dès février 1902, de fonder un Comité de défense républicaine ${ }^{104}$. Dès lors, les loges allaient se transformer en d'efficaces cellules de renseignement prêtes à seconder une République qui cherchait à s'assurer définitivement le contrôle de l'État. D'autant que les grands corps traditionnels ne s'étaient pas encore relevés de la tempête qu'ils avaient traversée quelques années plus tôt et que la lutte anticléricale allait devoir être relancée dans la haute fonction publique pour mettre enfin le personnel en adéquation avec les institutions ${ }^{105}$.

24 Encouragé par sa majorité radicale après le succès du «Bloc » aux élections de 1902, le Président du Conseil avait d'ailleurs aussitôt affirmé sa préoccupation de garantir le loyalisme de l'administration à l'égard du régime. Dans un contexte d'antimilitarisme grandissant et de concert avec André, ministre de la guerre, Combes avait engagé la démocratisation d'un corps resté par trop aux mains des notables et tenté de rendre tout son prestige à l'armée en épurant quelques postes clés ${ }^{106}$. Mais pour réparer les injustices faites aux officiers républicains dans leur avancement et démasquer les opposants qui constituaient une menace ${ }^{107}$, le ministre avait aussi dû chercher à recouper les informations fournies par des subordonnés dont il se méfiait ${ }^{108}$. Il avait 
mandé rue Cadet le capitaine Mollin, officier maçon de son cabinet, et au terme des pourparlers engagés avec le Président du Conseil de l'Ordre du Grand Orient, il avait été convenu que le frère Vadécard, secrétaire général, serait chargé de trouver en province des interlocuteurs susceptibles de rédiger des fiches détaillées à l'intention du ministre ${ }^{109}$. Ces dernières, demandées à tous les responsables des loges dont relevait une ville de garnison, devaient comporter les choix politiques des officiers, leurs pratiques religieuses, leurs fréquentations ou encore l'éducation dispensée à leurs enfants ${ }^{110}$. Mais à la suite d'un incident survenu à Châlons-sur-Marne et des graves fuites qui en découlèrent, Vadecard décida bientôt d'écarter «de son réseau d'informateurs tous les vénérables qui ne lui inspiraient qu'une confiance mitigée [...] et ne sélectionna [...] que 300 correspondants dont un certain nombre n'étaient du reste pas vénérables" "111. Dans le Maine-et-Loire, ce fut alors Jeanvrot, déjà largement impliqué dans l'œuvre de défense républicaine, qui devint l'agent de renseignement du Grand Orient et le responsable de l'entreprise d'espionnage du Ministère. Sa position au sein de la haute administration du département et son engagement dans des réseaux extra-professionnels proches de la sphère politique l'avaient en effet prédisposé à cette mission d'infiltration méthodique. Il allait l'accomplir durant deux ans, jusqu'à ce que les révélations sur le scandale ne le projètent sur le devant de la scène et le fasse vaciller sur son siège de conseiller.

L'Affaire des fiches éclata au grand jour à la fin de l'année 1904, après qu'un employé au secrétariat du Grand Orient de France, le frère Bidegain ${ }^{112}$, eut fourni au député nationaliste Guyot de Villeneuve, certains dossiers d'officiers hostiles à la République. Profitant de la séance parlementaire du 28 octobre, ce dernier révéla en effet la constitution du fichier nominatif et son collègue Rousset dénonça la surveillance pratiquée sur l'armée depuis 1901. Ce fut un tollé général à l'Assemblée, la presse parisienne s'empara aussitôt des divulgations pour fustiger un régime corrompu et les feuilles réactionnaires locales relayèrent le scandale en opérant une véritable « chasse aux sorcières ». Le ministre tenta bien de résister aux attaques mais contraint de reconnaître les faits, il dut donner sa démission et entraîna le cabinet dans sa chute ${ }^{113}$. Le parfum de scandale qui s'était ainsi répandu dans la capitale éclaboussa bientôt en province les protagonistes de l'Affaire qui avaient servi d'efficaces relais. Se sentant menacé, Jeanvrot rédigea, quelques jours plus tard, une lettre dans laquelle il affirmait n'avoir jamais fourni ni transmis sur des officiers de l'armée active « aucune note ou renseignement destinés à être communiqué au capitaine Mollin ou versés dans un bureau du Ministère de la Guerre " ${ }^{114}$. Et il y assurait aussi qu'avant l'interpellation à la Chambre, il avait ignoré à la fois l'identité de l'officier incriminé et l'existence du bureau en question. Mais avec cette autojustification anticipée, Jeanvrot ne venait-il pas au contraire de lever le voile sur ses agissements? Et comment, lui qui était alors membre du Conseil de l'Ordre du Grand Orient pouvait-il encore feindre d'ignorer les raisons du système mis en place? Certes il reconnaissait que depuis deux ans, le secrétaire du Conseil de l'Ordre lui avait demandé quelques renseignements confidentiels sur l'attitude politique de trois ou quatre officiers ayant leurs quartiers à Angers. Mais il soutenait que n'en connaissant aucun personnellement et «ayant tout lieu de croire qu'ils étaient destinés à des sénateurs et députés amis [...] souvent harcelés de sollicitations ", il n'avait fait que remettre ces feuilles à quelques personnes "en situation de pouvoir les satisfaire» ou les avait expédiées à Paris sans même prendre connaissance de leur contenu. Par ce biais, il entendait donc se défendre des attaques portées contre lui comme des arrières pensées que d'aucuns avaient voulu lui 
prêter. Et pour plaider sa bonne foi, il ajoutait même que c'était par les journaux qu'il avait appris "l'usage abusif et blâmable [...] fait de ces notes confidentielles, par la destination qu'on leur avait donnée à (son) insu » et que, « ne voulant accepter à aucun titre la responsabilité de ce procédé indigne " ${ }^{115}$, il avait aussitôt donné sa démission du Conseil de l'Ordre du Grand orient et de la loge angevine.

Néanmoins les passions continuaient à se déchaîner à Angers et un mois jour pour jour après l'interpellation de Guyot à la Chambre, une Lettre ouverte au premier président de la Cour d'Angers parut à la Une du Journal de Maine-et-Loire pour dénoncer le conseiller comme "l'un des membres les plus actifs de l'agence d'espionnage du Grand Orient ${ }^{116}$. Ce dernier n'ayant pas démenti publiquement son implication, le rédacteur anonyme stigmatisait les actes dont il s'était rendu coupable et qui avaient entaché son honneur de fonctionnaire. Considérant que " cette délation des officiers [...] organisée dans l'ombre [...] par la Franc-Maçonnerie » n'était qu'une trahison doublée d'une lâcheté et que leurs auteurs étaient des "êtres vils et méprisables, indignes de toute estime et de tout respect [au vu de] leur situation sociale élevée ", il appelait de ses vœux des mesures disciplinaires. Selon lui, Jeanvrot s'était disqualifié comme magistrat aux yeux des justiciables et de ses collègues «qu'il espionn[ait] sans doute comme les officiers", et devait mériter la juste répression de ses pairs. Compromis par un magistrat sans scrupule, l'honneur et la dignité du corps judiciaire devaient être défendus, menacé par des agissements déloyaux, le prestige de la justice devait être relevé, et la solution qu'il préconisait était d'écarter le fautif de la magistrature ou à tout le moins, que le premier président repoussât « une solidarité infamante avec un collègue indigne ${ }^{117}$.

À la suite de cet article de presse venimeux dont l'écho se fit entendre jusque dans les couloirs du Palais, une enquête fut diligentée par la Chancellerie, demandant au premier président de la Cour de provoquer d'urgence les explications de Jeanvrot ${ }^{118}$. Il fallait en effet que les autorités ne tardent pas à s'enquérir de la réalité des faits dénoncés par une presse toujours plus hostile et qui se livrait désormais à une attaque en règle contre toute la magistrature, en répandant les allégations les plus fallacieuses. Les individus soupçonnés d'avoir participé à l'entreprise étaient en effet l'objet de propos de plus en plus outranciers et ceux d'entre eux qui étaient des fonctionnaires de la République, voyaient leur honneur et leur dignité outrageusement bafoués quand ils n'étaient pas menacés jusque dans leur intégrité physique. Jeanvrot, qui pendant plusieurs semaines avait été traîné dans la boue par les journaux locaux, fut bientôt l'objet d'agissements coupables sur la place d'Angers: le 26 novembre 1904 on pu retrouver dans les urinoirs de la ville d'innombrables placards apposés par des inconnus avec l'inscription «A l'égout f $\mathrm{f}_{\mathrm{E}}^{\mathrm{E}} \mathrm{J}$ Jeanvrot, la casserole ! » et le 8 décembre suivant, de jeunes étudiants de l'Université catholique allèrent le conspuer sous les fenêtres de son domicile, jusqu'à ce que l'arrivée des forces de l'ordre ne les contraignent à se réfugier dans l'établissement d'enseignement voisin ${ }^{119}$. Malgré l'ampleur des rumeurs qu'on laissait ainsi courir, la violence des actes dirigés contre le conseiller et les évidences qui apparaissaient désormais au grand jour sur son implication dans le scandale, le premier président de la Cour d'Angers choisit de faire peu de cas des réclamations d'une opinion publique conservatrice déchaînée ${ }^{120}$. S'appuyant sur les dénégations de Jeanvrot et animé d'un profond esprit de corps ${ }^{121}$, il tenta en effet de défendre son subordonné en minimisant dans le rapport qu'il adressa à Paris, l'intensité de la polémique suscitée à Angers ${ }^{122}$. Pour autant, la Chancellerie ne put se contenter de ses explications et afin de savoir s'il y avait lieu d'exercer une 
mesure disciplinaire à son encontre, convoqua le conseiller angevin dans ses bureaux le 5 décembre 1905, pour qu'il y rencontre le directeur du personnel ${ }^{123}$. Là, Jeanvrot qui ne pouvait plus ignorer qu'une demande de démission lui serait demandée verbalement, fit une ultime tentative pour échapper au sort professionnel qui lui était promis et réclama son admission à la retraite au motif d'infirmités graves. La Chancellerie, peu dupe du subterfuge employé, fit savoir quelque temps plus tard à ses supérieurs que le certificat médical produit à l'appui de sa demande d'admission ne paraissait pas suffisamment probant pour qu'il lui soit fait application de l'article 11 de la loi du 9 juin 1853 et décida de laisser la solution en suspens. Sa hiérarchie, les membres des loges angevines et les comités républicains de Maine-et-Loire qui tentèrent de le soutenir ne s'y trompèrent pas. Envoyant des adresses de félicitations à Emile Combes après la chute de son cabinet pour sa politique salutaire, ils rappelèrent leur fierté d'avoir vu l'un des leurs prêter son concours à l'œuvre d'assainissement de l'armée et d'avoir été à l'avant-garde du combat pour la défense du régime ${ }^{124}$. Particulièrement élogieuse sur l'action menée par leur frère mais également préoccupée du sort qui lui avait été fait, la loge Travail et Perfection émit à cette occasion le vœu qu'on fasse droit à sa demande et qu'une caisse nationale de solidarité soit organisée en faveur de tous les maçons qui, comme lui, avaient été victimes de l'Affaire. Par leur sollicitude au lendemain même du scandale, ils allaient ainsi pouvoir contrecarrer la résistance des bureaux et éviter au conseiller le désagrément d'une mise à l'écart d'office, en obtenant du cabinet Rouvier que Jeanvrot soit admis à la retraite dès le 18 janvier 1905 et que lui soit conféré l'honorariat. Mais à l'heure où la séparation de l'Église et de l'État allait mobiliser les énergies progressistes, c'était néanmoins l'un des magistrats républicains les plus actifs de la Cour d'Angers qui était ainsi contraint de mettre un terme à sa carrière au nom des convictions radicales qu'il n'avait jamais reniées mais qui l'avaient conduit à la compromission ${ }^{125}$.

Rompu aux affaires par plus de trente-quatre années de services, celui qui s'effaçait ainsi à l'aube du nouveau siècle, s'était assuré une véritable autorité sur son siège de conseiller et avait marqué de son empreinte judiciaire la compagnie angevine. Maintes fois il avait pu appréhender les méandres de la procédure et sa connaissance approfondie des codes comme l'appui de ses réseaux, l'avaient amené très tôt à dépasser sa sphère provinciale pour soutenir la vitalité de revues juridiques et s'engager dans le mouvement réformateur. Grâce au déploiement de son savoir et de ses compétences, qui témoignait du processus d'acculturation juridique de la petite bourgeoisie, il avait pu se forger une position reconnue au sein de l'élite expertale et participer ainsi à la montée des capacités au sein de la magistrature. Décidant de rompre avec les discours incantatoires et les figures de rhétorique sur une réforme de la justice toujours annoncée mais repoussée, il fuit à l'initiarive du premier Congrès de la réforme judiciaire qui devait être l'instrument d'une réforme sociale plus large ${ }^{126}$. Animé d'un égalitarisme viscéral, nourri par un contact quotidien avec les abus du favoritisme, du népotisme et du clientélisme, il allait inlassablement prôner l'instauration de règles méritocratiques pour l'avancement des juges, réclamer l'élection de ces derniers et appeler de ses vœux l'ouverture sociale du corps. Mais ce combat qui procédait d'une volonté de rationalisation du système judiciaire et participait du dessein d'instaurer une justice populaire, ne fut pas sans conséquence sur son parcours. Certes, le 
fonctionnaire avait su honorer la magistrature dès 1870, «en servant avec un dévouement absolu la République » ${ }^{127}$, mais le franc-maçon zélé s'était « trop occupé de politique, de religion et de querelles locales " ${ }^{128}$ pour obtenir la consécration professionnelle que sa science, ses mérites et ses services judiciaires lui promettaient. En acquérant « un grade élevé dans la Franc-Maçonnerie angevine qu'il dirige[ait] » 129 et plus tard, en prenant rang de dignitaire au sein du Grand Orient de France, il avait assuré du radicalisme de ses opinions et du glissement de ses activités extra-judiciaires du champ intellectuel vers le champ politique. Signalé à la Chancellerie pour avoir mis son indépendance au service d'un avant-gardisme jugé outrancier par ses chefs, jamais son appartenance au corps judiciaire n'avait pu cependant altérer son engagement dans l'espace public. Anticlérical par doctrine philosophique autant que par conviction politique, il s'était mis continûment aux avant-postes pour la promotion de l'idée laïque et la défense de la République. Et en levant le voile sur ses actions souterraines de propagande en faveur de la cause radicale, l'Affaire des fiches était venue révéler la lutte ardente que lui et ses frères maçons avaient pu mener au cœur de l'État pour l'enracinement du régime.

Par ses choix, Jeanvrot avait bousculé le conformisme des mœurs judiciaires de son temps et ainsi marqué les lignes de clivage existant au sein de la magistrature. Le dernier combat qu'il avait livré contre l'Arche sainte conservatrice avait précipité la fin d'une carrière judiciaire mouvementée et motivée le repli du citoyen engagé dans la sphère privée. Mais par sa trajectoire et ses engagements, il avait aussi assuré du triomphe prochain des «nouvelles couches» parmi les fonctionnaires de l'ordre judiciaire et confirmé que le succès des idéaux républicains pour lesquels il avait toujours combattu y paraissait désormais acquis ${ }^{130}$.

\section{NOTES}

1.. Pierre BOURDIEU, "L'illusion biographique », dans Actes de la Recherche en Sciences Sociales, n 62-63, juin 1983, pp. 69-72 ; Giovanni LEVI, « Les usages de la biographie », dans Annales. Economies, Sociétés, Civilisations, ${ }^{\circ} 6$, novembre-décembre 1989, pp. 1325-1335; Jean-Claude PASSERON, « Biographie, flux, itinéraires, trajectoires », dans Revue française de sociologie, $\mathrm{n}^{\circ} 1$, janvier-mars, tome 31, 1990, pp. 3-22.

2.. (Archives nationales) BB6II. 956 3383. Dossier Jeanvrot. Extrait de l'état civil de Montreuil-sur-Mer. (Une notice individuelle établie en 1881 par les chefs de la Cour d'Angers signale ensuite ce père comme greffier en chef du tribunal de la ville. L'examen des différentes pièces du dossier confirme que sa charge d'avoué ne lui offrait pas les ressources escomptées et qu'il avait succédé à son beau frère dans ces fonctions de greffier pour éviter un déclassement social).

3.. Ibidem. Dépêche du procureur général d'Amiens au Garde des Sceaux, 3 mai 1881.

4.. Sur les rapports entre barreaux et politique, voir Catherine FILLON, « Les avocats lyonnais et la République (1870-1914) : la tentation du pouvoir et du contre-pouvoir ", dans Bruno DUMONS, Gilles POLLET [dir.], Élites et pouvoirs locaux. La France du Sud-Est sous la Troisième République, Lyon, Presses universitaires de Lyon, 1999, pp. 43-59 ; Gilles 
LE BEGUEC [dir.], Barreau, politique et culture à la Belle époque, Limoges, Presses universitaires de Limoges, 1997, 246 p; Christophe CHARLE, « Le déclin de la République des avocats ", dans Pierre BIRNBAUM [dir.], La France de l'affaire Dreyfus, Paris, Éditions Gallimard, 1994, pp. 56-86 ; Jean-Louis DEBRÉ, La Justice au XIXe siècle. La République des avocats, Paris, Librairie académique Perrin, 1984, $382 \mathrm{p}$.

5.. Rapport du premier président de la Cour de Douai, 8 juin 1872.

6.. Sur les avocats des XIX et $\mathrm{XX}^{\mathrm{e}}$ siècles, voir Jean-Louis HALPÉRIN [dir.], Avocats et notaires en Europe. Les professions judiciaires et juridiques dans l'histoire contemporaine, Paris, L.G.D.J., 1996, 318 p; Lucien KARPIK, Les Avocats. Entre l'État, le public et le marché. XVIII ${ }^{e_{-}}$ XXe siècles, Paris, Éditions Gallimard, 1995, 482 p; Christophe CHARLE, « La bourgeoisie de robe en France au XIX ${ }^{\mathrm{e}}$ siècle », dans Le Mouvement social, $\mathrm{n}^{\circ} 181$, octobre-décembre 1997, pp. 53-72 et « Le recrutement des avocats parisiens (1880-1914) », dans Gilles LE BEGUEC [dir.], Avocats et Barreaux en France. 1910-1930, Nancy, Presses Universitaires de Nancy, 1994, pp. 21-34 ; Pascal PLAS, « Le barreau, carrefour des élites locales : l'exemple du limousin ", dans Les Élites fins de siècles. XIX ${ }^{e}-X X^{e}$ siècles, textes réunis par Sylvie GUILLAUME, Bordeaux, Maison des sciences de l'homme d'Aquitaine, 1992, pp. 55-77.

7.. Sur cette magistrature coloniale, voir Jean-Pierre ROYER, Renée MARTINAGE, Pierre LECOCQ, Juges et notables au XIXe siècle, Paris, Presses Universitaires de France, 1982, pp. 225-242 ; Jean-Pierre ROYER, « Portrait du juriste colonial : magistrats et administrateurs dans l'Afrique du XIX siècle ", dans Revue française d'administration publique, 1987, ${ }^{\circ} 42$, pp. 91-101, et Bernard DURAND, La justice et le droit : instruments d'une stratégie coloniale Rapport à la Mission de recherche Droit et Justice. Ministère de la justice, novembre 2001.

8.. Concernant les mouvements judiciaires opérés en 1870, voir Jean-Pierre ROYER, Histoire de la justice en France, Paris, Presses Universitaires de France, 1995, pp. 527-533, et Robert BOUCHERY, Jean-Pierre MACHELON, «L'épuration républicaine. 1870-1871(Siège-Parquet), 1872-1882 (Parquet) ", dans Histoire de la justice, $\mathrm{n}^{\circ}$ 6, 1994, pp. 69-86.

9.. Sur l'usage des présentations et les conditions de recrutement, voir André DESHEDIN, Étude sur le recrutement et l'avancement de la magistrature, Paris, Librairie Nouvelle de droit et de jurisprudence, 1908, 520 p.

10.. Lettre du procureur général de Douai au Garde des Sceaux, 13 Août 1877.

11.. Rapport du procureur général de Douai au Garde des Sceaux, 4 juin 1872.

12.. Rapport du premier président de la Cour de Douai au Garde des Sceaux, 8 juin 1872.

13.. Idem.

14.. Idem.

15.. Propos du très conservateur procureur général de Douai qui avait vu Jeanvrot débuter sous les auspices des républicains portés au pouvoir en 1870. Lettre au Garde des Sceaux, 4 juin 1872.

16.. Rapport du premier président de la Cour de Douai, 8 juin 1872.

17.. Le premier président de la Cour de Douai soulignant en juin 1872, que « Jeanvrot a[vait] gagné de l'instruction, l'habitude de la parole et l'expérience des affaires, [qu'il avait] l'esprit juste ».

18.. Lettre du procureur général de Bastia au Garde des Sceaux, 2 août 1872.

19.. Rapport du procureur général de Bastia au Garde des Sceaux, 8 janvier 1874.

20.. Idem.

21.. Lettre du procureur d'Ajaccio au procureur général, 24 décembre 1875. 
22.. Jean-Pierre ROYER, « La notation des magistrats en France depuis 1850 », dans Être juge demain. Belgique, Espagne, France, Italie, Pays-Bas, Portugal et République fédérale allemande, Lille, Presses universitaires de Lille, 1983, pp. 229-241, et « La magistrature en Europe ", dans Revue politique et parlementaire, n 954, juillet-août, 1991, pp. 24-27. 23. Lettre du procureur général de Bastia au Garde des Sceaux, 21 avril 1877.

24.. Recommandation de Mention, Merlin, Pierre Legrand et Masure au Garde des Sceaux, 5 août 1876.

25. Lettre de Jeanvrot au Garde des Sceaux, 9 janvier 1877. Déjà en 1876, il avait sollicité un avancement hors de l'île et adressé un exemplaire de son étude sur $\mathrm{La}$ législation de l'Algérie comprenant l'état actuel de l'organisation politique, administrative, pensant que c'était là un titre nouveau à l'appui de sa demande.

26.. Lettre du procureur général de Douai, 17 février 1879.

27.. Lettre d'Alfred Girard, député du Nord au Garde des Sceaux, 22 février 1881. Sur le ministère public, voir Jean-Marie CARBASSE, Histoire du parquet, Paris, Presses Universitaires de France, 2000, 333 p.

28. Jean-Luc MARAIS, « Pourquoi le Maine-et-Loire n'est-il pas devenu républicain au début de la Troisième République ? ", dans Annales de Bretagne et des Pays de l'Ouest, tome 99, n 4, 1992, pp. 441-455.

29. Notice individuelle établie par le procureur général d'Angers, 12 août 1881.

30.. Sur l'exécution des décrets et le rôle tenu par Jeanvrot, voir notre article « La magistrature dans la balance au temps de la République combattante : l'affaire des décrets, prélude à la révolution judiciaire dans l'Ouest de la France (1879-1880) », dans Histoire de la Justice, 2003, n 15, pp. 199-218.

31.. Présentation pour une place de substitut du procureur général, au Garde des Sceaux, 29 juin 1880.

32.. Dans ce rapport du 12 août 1881, il était signalé comme un " travailleur émérite ", d'une science « hors du commun », d'une instruction « hors ligne », doué d'un style « correct et d'une précision rare », d'un jugement « sûr et prompt » et d'une « impartialité parfaite ».

33.. Rapport du procureur général d'Angers concernant les assises du Maine-et-Loire, $1^{\mathrm{er}}$ trimestre 1881.

34.. Notice individuelle, août 1881 («Fermeté ordinaire [...] élocution un peu froide et hésitante [...] redoute l'audience où il aurait cependant de réels succès s'il parvenait à triompher de sa timidité »).

35.. Lettre de présentation du procureur général au Garde des Sceaux, 22 mai 1882.

36. Des représentants du Pas-de-Calais, le directeur et rédacteur en chef du journal La Paix, le franc-maçon Colfavru et l'avocat Lagache de Saint Gest avaient appelé de leurs vœux la nomination de ce « magistrat garanti bon teint » à la Cour d'Amiens pour « infuser un peu de sang républicain à cette Cour archi-réactionnaire » (Lettre au Garde des Sceaux, 28 mars 1881).

37. Sur cette épuration judiciaire, consulter Jean-Pierre ROYER, ouv. cité, pp. 596-600 ; Jean-Pierre MACHELON, La République contre les libertés?, Paris, Presses de la Fondation Nationale des Sciences Politiques, 1976, pp. 296-302, et du même auteur «L'épuration républicaine. La loi du 30 août 1883 ", dans Histoire de la justice, nº 6, 1994, pp. 87-101.

38.. Rapport du procureur général d'Angers, 27 novembre 1893.

39.. Notice individuelle constituée par le procureur général d'Angers, 7 avril 1887.

40.. Présentation du procureur général d'Angers pour l'obtention de la Légion d'honneur, 13 novembre 1896. 
41.. Recommandation du député Laferre au Garde des Sceaux, 27 avril 1900.

42.. Notamment Fernand Rabier, député, Maxime Lecomte, sénateur, Henri Brisson et le Ministre de la marine.

43.. Christophe CHARLE, « Les spécificités de la magistrature française en Europe (XIX ${ }^{\text {- }}$ XX siècles) », dans Crises, $\mathrm{n}^{\circ} 4$, 1994, pp. 61-68, et « Etat et magistrats. Les origines d'une crise prolongée ", dans Actes de la Recherche en Sciences sociales, $\mathrm{n}^{\circ}$ 96-97, mars 1993, pp. 39-48.

44.. Sur la réserve des élites judiciaires et administratives, voir notamment Alain BANCAUD, «La réserve privée du juge », dans Droit et Société, n 20-21, 1992, pp. 229-247 et Pierre BOURDIEU, La Noblesse d'État, Paris, Éditions. de Minuit, 1989, p. 154 et suiv. 45.. Dès 1892 , le chef du parquet d'Angers avait estimé que Jeanvrot ne pouvait plus espérer d'avancement dans son ressort, mais que s'il avait consenti à aller dans une ville plus importante, où se trouvait une compagnie nombreuse dans laquelle il eût été moins remarqué, il eût fait un excellent Président de Chambre.

46.. Notice du procureur général de Bastia, 8 janvier 1874.

47.. Notices individuelles des 12 août 1881 et 4 juin 1892 (« Vit très retiré et ne va chez personne »).

48.. Selon le procureur général d'Angers, Jeanvrot jouissait « d'une fortune personnelle sinon considérable, au moins largement suffisante pour ses goûts modestes » (Notice, 27 mars 1881), correspondant à « environ 10 à 12.000 francs de revenus » (Notice, 12 août 1881).

49.. Par diverses circulaires (notamment celles des 15 août 1876 et 10 janvier 1879), les Gardes des Sceaux avaient institué au Ministère un comité chargé de leur rendre compte des travaux et publications des magistrats qui, en signalant ainsi leurs mérites, pouvaient acquérir des titres supplémentaires à un avancement.

50.. Notice individuelle établie par le procureur général d'Angers, 12 août 1881.

51.. Voir l'opuscule intitulé Le 14 juillet, histoire de la fête nationale et de la prise de la Bastille, Paris, Éditions Charavay, 1886, 141 p., dans lequel il s'en prend à la monarchie et aux féodalités, glorifie les acteurs de cet épisode «mythologique» et souligne l'absolue nécessité de faire vivre l'héritage révolutionnaire.

52.. Soucieux de rendre intelligible les idéaux nés de la Révolution, Jeanvrot n'hésita pas à faire œuvre de pédagogie en publiant notamment aux éditions Charavay frères en 1885, un ouvrage de vulgarisation sous le pseudonyme de Narjo, intitulé La Patrie française, livre de lecture courante à l'usage des écoles primaires, cours moyen et supérieur, par Charles Comte.

53.. Spécialiste de la législation française, il apporta ponctuellement sa contribution à la connaissance des textes étrangers comme en témoigne La loi allemande du 23 octobre 1878 contre les tendances démocratiques socialistes, traduction et commentaires, publiée à Paris chez A. Cotillon en 1879.

54.. Manuel de la police des cultes, à l'usage des maires et fonctionnaires de l'ordre administratif et judiciaire, Angers, A. Dedouvres, 1880-1890, 2 volumes.

55.. De l'application des décrets du 29 mars 1880 sur les congrégations... avec un appendice contenant un examen critique de ma consultation de Me Rousse, Paris, A. Cotillon, 1880.

56.. Lettre de recommandation d'Alfred Girard, député du Nord au Garde des Sceaux, 22 février 1881.

57.. Idem.

58.. Recommandation du procureur général d'Amiens, 18 mai 1881.

59.. Paris, A. Cotillon et Marescq aîné, 2 volumes, 1882-1883. 
60.. Sur ce point, voir Jacques POUMAREDE, « L'élection des juges en débat sous la Troisième République », dans Jacques KRYNEN [dir.], L'Élection des juges. Études historiques françaises et contemporaines, Paris, Presses universitaires de France, 1999, pp. 113-136.

61.. Présentation de Jeanvrot par le procureur général d'Amiens pour une place de conseiller, mai 1881.

62.. Rapport spécial du procureur général d'Angers au Garde des Sceaux, 27 mars 1881. «Chercheur comme il y en a peu [...] nul n'est plus à même que lui d'étudier une question dans tous ses précédents, ses origines et ses ramifications les plus éloignées. Il rédige avec une véritable facilité et une grande sûreté de plume, [...] peu de magistrats connaissent autant de droit que lui ».

63.. Présentation du procureur général d'Angers pour une place de conseiller, 22 mars 1882.

64.. Rapport du procureur général d'Angers sur les assises du Maine-et-Loire, $1^{\mathrm{er}}$ trimestre 1881.

65.. Ce vif intérêt du Parlement pour les travaux de Jeanvrot est particulièrement perceptible dans la recommandation que le député Colfavru adresse au Garde des Sceaux le 20 octobre 1886 : « Beaucoup d'entre nous connaissent les remarquables ouvrages de M. Jeanvrot. Ils ont été souvent cités à la tribune parlementaire lors de la discussion sur la réforme judiciaire en 1882 [...] nous aurons à le citer souvent à cause de son érudition et de sa science lorsque nous aurons à reprendre ce grave débat devant la Chambre et devant le pays. Je vous les ai fait remettre l'an dernier et vous avez bien accueilli tous les ouvrages de M. Jeanvrot ", Arch. nat. BB6II, 956. 3383. Lettre pour un avancement à la Cour de Paris.

66. Faisant paraître La suppression du serment : origines et état de la question, état de la jurisprudence, le projet de loi du Sénat, le projet de la Chambre des députés (Paris, ChevalierMarescq, 1887), De la limitation du droit de tester des célibataires ou le Code pratique de la presse et de l'imprimerie, Angers, G. Paré, 1890 et 1894.

67.. Expression empruntée à Christian TOPALOV [dir.], Laboratoires du nouveau siècle. La nébuleuse réformatrice et ses réseaux en France (1880-1914), Paris, Éditions de l'ÉHESS, 1999, $574 \mathrm{p}$.

68. Sur la participation des élites judiciaires au processus de réforme et le rôle d'expertise de certaines sociétés juridiques, voir les études de Martine KALUSZYNSKI, « Réformer la société. Les hommes de la société générale des prisons. 1877-1900 », dans Genèses, n² 28, 1997, pp. 75-93, «Construire la loi. La Société générale des prisons (1877-1900) ", dans Martine KALUSZYNSKI et Sophie WAHNICH [dir.], L'État contre la politique? Les expressions historiques de l'étatisation, Paris, Éditions L'Harmattan, 1998, pp. 205-221, « Les artisans de la loi. Espaces juridico-politiques en France sous la Troisième République », dans Droit et Société, 1998, pp. 535-562, et « Qui produit la loi ?. Espace(s) juridique(s), espace(s) politique(s) avant la Première Guerre mondiale », dans MarcOlivier BARUCH, Vincent DUCLERT, [dir.], Serviteurs de l'État. Une histoire politique de l'administration française (1875-1945), Paris, Éditions La Découverte, 2000, pp. 83-95. 69.. Bien que le programme présenté par Jeanvrot dans le premier numéro de la revue laissait penser que les préoccupations majeures se limiteraient au Code de procédure et à la législation civile, l'examen des contributions apportées montrent que le personnel judiciaire (notamment celui des justices de paix - nombre, compétences, mode de nomination) et les auxiliaires de justice (avocats, avoués) ont en réalité été au cœur des travaux du groupe. 
70.. Frédéric CHAUVAUD, «L'insaisissable modèle. L'identité brouillée de la justice républicaine (1880-1940) », dans Marc-Olivier BARUCH et Vincent DUCLERT [dir.], ouv. cité, p. 336.

71.. Présentation du procureur général d'Angers pour la Légion d'Honneur, 13 novembre 1896

72.. Voir les numéros du Patriote de l'Ouest qui annoncent et relatent l'événement à partir du 4 juin 1886.

73.. Rapport confidentiel, 6 juin 1886 : « Il est regrettable que M. Jeanvrot tienne chez lui une réunion ayant pour but de critiquer et réformer l'organisation de la magistrature à laquelle il appartient dans un rang élevé ».

74.. Notamment M.M. de Montluc, conseiller, Chudeau, président de chambre et Cournot, substitut du procureur général, qui collaboraient de manière très active à la Revue de la Réforme judiciaire depuis sa création.

75.. « La presse angevine, surtout [...] réactionnaire, s'occupera d'une manière spéciale de cette assemblée, d'autant plus qu'un certain nombre d'anciens magistrats dépossédés lors de la réforme du personnel judiciaire et très hostiles à la magistrature actuelle, résident à Angers et y ont naturellement cette presse pour organe ».

76.. Rapport du procureur général au Garde des Sceaux, 15 juin 1886 : « Un assez grand nombre d'adhésions sont parvenues aux organisateurs du Congrès parmi lesquelles celles de M. Granet, ministre des Postes et Télégraphes, Hippolyte Dubois, conseiller d'Etat, Dide, sénateur, Yves Guyot, Rivière, Bovier-Laperrière, de Hérédia, Remoiville, Hubbard et Periller, députés, etc ».

77.. Idem.

78.. Article dont ils jugeaient le contenu très insuffisant puisqu'il n'attribuait aux juges de paix de compétence en premier ressort que jusqu'à 1500 francs.

79.. Programmée à Paris pour le mois d'août 1887, cette seconde réunion bénéficia, contrairement à sa devancière, de toute la publicité nécessaire. Tenue au siège du Grand Orient sous la présidence de Colfavru, les 9-10 septembre 1887, elle fut l'occasion de nouvelles propositions de réforme, notamment de la part du conseiller angevin de Montluc. Et lors des congrès suivants (septembre 1888, août 1889), Jeanvrot qui représentait le ressort d'Angers, intervint sur l'organisation d'un jury correctionnel, la criminalité et la liberté d'association.

80.. Sur la crise d'identité des magistrats à la fin du XIX siècle, sur les représentations de la société judiciaire et la désacralisation de la fonction, voir notamment les contributions de Jean-Claude FARCY et de Frédéric CHAUVAUD dans les actes du colloque de Royaumont, Le Sanglot judiciaire. La désacralisation de la justice (VIII ${ }^{e}-\mathrm{XX}^{e}$ siècles), Paris, Éditions Créaphis, 1999, 230 p. ; Frédéric CHAUVAUD, « Le jugement de Marianne. La Troisième République et ses juges », dans Crises, n 4, 1994, pp. 69-75. 81.. Voir Christophe CHARLE, « Légitimités en péril. éléments pour une histoire comparée des élites et de l'État en France et en Europe occidentale (XIX ${ }^{\mathrm{e}}-\mathrm{XX}^{\mathrm{e}}$ siècles) ", dans Actes de la recherche en sciences sociales, $n^{\circ} 116-117$, mars, 1997, pp. 39-52, et du même auteur Les Élites de la République. 1880-1900, Paris, Librairie Arthème Fayard, 1987, $556 \mathrm{p}$.

82.. Arch. Grand Orient de France, Res FM2. 38, Composition de la loge Travail et Perfection, 1875-1899.

83.. Voir Jean-Luc MARAIS, « La contre-offensive catholique (1870-1906) », dans François LEBRUN [dir.], Histoire des diocèses de France, $n^{\circ} 13$. Angers, Paris, Beauchesne, 
1981, pp. 213-222 ; Jacques GADILLE, La Pensée et l'action des évêques français au début de la Troisième République (1870-1883), Paris, Éditions Hachette, 1967, 2 tomes, 351 et 334 p. 84.. S'ils avaient pâti de la perte de situations souvent prestigieuses au sein du corps judiciaire, nombre de ces anciens magistrats avaient retrouvé une activité professionnelle à la suite de l'épuration de 1883 - journalisme, barreau - et avaient su préserver une position sociale enviée dans la cité.

85.. Sur la dénonciation cléricale des pouvoirs occultes des maçons au sein de l'appareil d'Etat, voir Michel JARRIGE, L'Église et les francs-maçons dans la tourmente. Croisade de la revue la Franc-Maçonnerie démasquée. 1884-1899, Paris, Éditions Arguments, 1999, 291 p. ; Jacques LEMAIRE, L'Antimaçonnisme. Aspects généraux (1738-1998), Paris, Éditions maçonniques de France, 1998, 127 p. ; P. HERVIEU, « De l'antimaçonnisme en France (fin XIX ${ }^{\mathrm{e}}$-début XX $\mathrm{X}^{\mathrm{e}}$ siècle) », dans Chronique d'histoire maçonnique, 1988, n 41, pp. 105-114.

86.. Voir l'article provocateur de L'Union de l'Ouest daté du 13 mai 1884 et la réplique de Jeanvrot insérée dans Le Patriote de l'Ouest du lendemain.

87. Sur cette question, on consultera Le serment, Actes du colloque international organisé du 25 au 27 mai 1989 par le CNRS et l'Université Paris 10-Nanterre, Paris, CNRS éditions., 2 volumes, XXV-457 p. et VIII-484 p.

88. Voir notamment André COMBES, Histoire de la Franc-Maçonnerie au XIX ${ }^{e}$ siècle, vol. 2, Paris, Éditions du Rocher, 1999, 429 p. et Daniel LIGOU [dir.], Histoire des francs-maçons en France, Toulouse, Privat, 1987, 412 p. Ce glissement avait d'ailleurs été nettement dénoncé par le pape Léon XIII dans son encyclique de 1884, où il appelait ouvertement à combattre les secrètes manœuvres anticatholiques de la Maçonnerie. En Anjou, l'examen des périodiques à partir des années 1880, montre du reste combien les détracteurs de la République se plaisaient à amplifier le moindre incident impliquant un fonctionnaire maçon pour mieux fustiger l'évolution de l'obédience.

89.. Arch. Grand Orient de France, Res FM2. 37, Composition de la loge Travail et Perfection, Orient d'Angers (1897-1898). On notera que le procureur général d'Angers ne mentionna officiellement l'affiliation de Jeanvrot à la Maçonnerie qu'en 1893.

90.. Terminologie maçonnique désignant le frère chargé à la fois de discuter et de traiter les affaires d'intérêt commun mais aussi d'aplanir les différends surgis entre les loges.

91.. Annuaire de la Loge Chapitre et Aéropage Travail et Perfection, Angers, Poitevin et Scipion, 1886, $24 \mathrm{p}$.

92.. Ce comité, doté d'une caisse spéciale pour son fonctionnement, allait superviser toutes les manifestations de propagande des loges (publications, conférences, etc). La position occupée en son sein par Jeanvrot témoignait certes de l'ancrage laïque du Grand Orient de France mais soulignait aussi qu'en Anjou, le conseiller devenait le portedrapeau des frères ligériens ralliés sous la bannière d'une République conquérante.

93.. Des hauts grades et des ateliers de perfection, discours de Dupin, Angers, A. Poitevin-V. Scipion, 1886, p. 8.

94.. Sur le tournant opéré par les maçons du Grand Orient lors du convent historique de 1877, voir notamment André COMBES, Le Grand Orient de France, tome 2. 1865-1914, Paris, Éditions. Maçonniques de France, Coll. Histoire, 2001, pp. 37-57 ; Daniel LIGOU, "L'évolution de la maçonnerie française au XIX ${ }^{\mathrm{e}}$ siècle », dans Jean SAGNES [dir.] Cent cinquante ans de Franc-Maçonnerie en France. 1789-1940, Béziers, Éditions de la Ville de Béziers, 1992, pp. 25-36.

95.. Des hauts grades et des ateliers de perfection, ouv. cité, p. 9. 
96.. Discours de Jeanvrot prononcé le 11 janvier 1885 à la loge Travail et Perfection, lors de l'initiation d'Allain-Targé, préfet de la Sarthe, et Lardin de Musset, sous-préfet d'Ancenis, Angers, A. Dedouvres, 1885, 16 p.

97.. Discours de Jeanvrot le 11 février 1884 à la loge Travail et Perfection, Angers, A. Dedouvres, $1884,32 \mathrm{p}$.

98. Voir André BOUTON, Marius LEPAGE, Histoire de la Franc-Maçonnerie dans la Mayenne (1756-1951), Le Mans, Le Monnoyer, 1951, 302 p ; André BOUTON, Les luttes ardentes des francs-maçons manceaux pour l'établissement de la République (1815-1914), Le Mans, Le Monnoyer, 1966, 396 p ; Jacques FENEANT, Franc-maçonnerie et sociétés secrètes en Val de Loire, Chambray, Éditions. CLD, 1986, 328 p.

99.. Article du Journal de Maine-et-Loire daté du 8 juin 1887, intitulé « Le F泡 Jeanvrot ». 100.. Rapport très confidentiel transmis à la Chancellerie par le procureur général d'Angers relatant cette affaire et soulignant que Jeanvrot était parvenu à faire adopter sa motion, 6 janvier 1886.

101.. Sur la libre pensée et ses rapports avec la Franc-Maçonnerie, on consultera l'ouvrage de Jacqueline LALOUETTE, La libre pensée en France. 1848-1940, Paris, Éditions Albin Michel, 1997, 636 p.

102.. Jacques FENEANT, Histoire de la Franc-Maçonnerie dans le Val de Loire (1745-1945), thèse d'État histoire, sous la direction de Daniel LIGOU, Université de Dijon, 1984, pp. 562-563.

103.. Voir Michel LAGRÉE, « Processions religieuses et violence démocratique dans la France de 1903 », dans French Historical Studies, n²1, volume 21, décembre 1998, pp. 77-99.

104.. Sur le soutien du Grand Orient de France à la politique du «Bloc », voir Emile COMBES, Mon ministère. mémoires (1902-1905), préface de Maurice SORRE, Paris, Éditions Plon, 1956, XVI-295 p ; Gabriel MERLE, Emile Combes, Paris, Librairie Arthème Fayard, 1995, $664 \mathrm{p}$.

105.. Voir notamment Jérôme HÉLIE, « L'arche sainte fracturée », dans Pierre BIRNBAUM [dir.], ouv. cité, pp. 226-250 et la contribution dans le même ouvrage de Jean-Pierre ROYER, « La magistrature déchirée », pp. 251-289.

106.. Il réalisa la promotion interne des sous-officiers, fit supprimer l'obligation de la dot pour les femmes d'officiers, imposa aux futurs St-Cyriens un an de service dans un corps de troupe et prépara la réduction du service à 2 ans ou la suppression des exemptions (loi votée dès 1905).

107. Sur les rapports entre l'Armée et la République, voir notamment Jérôme HÉLIE, « Les armes », dans Pierre NORA [dir.], Les lieux de mémoire, volume III., Paris, Éditions Gallimard, 1992, pp. 237-283, et Olivier FORCADE, Éric DUHAMEL, Philippe VIAL [dir.], Militaires en République (1870-1962). Les Officiers, le pouvoir et la vie publique en France, Paris, Publications de la Sorbonne, 1999, 734 p.

108.. Daniel LIGOU, Dictionnaire universel de la Franc-Maçonnerie, Paris, Éditions de Navarre, 1974, pp. 491-492. «Ne voulant pas se fier aux notes des commissions d'avancement, bourrées d'officiers cléricaux ou hostiles ».

109.. Voir Pierre CHEVALLIER, Histoire de la Franc-Maçonnerie française, tome III. La Maçonnerie : Église de la République (1877-1944), Paris, Librairie Arthème Fayard, 1975, pp. 94-96 ; François VINDÉ, L'Affaire des fiches, 1900-1904 : chronique d'un scandale, Paris, Éditions Universitaires, 1989, pp. 33-50 ; Serge BERSTEIN, « Les francs-maçons, La République et l'armée », dans L'Histoire, n 131, 1990, pp. 18-26. 
110.. Si l'on en croit Pierre CHEVALLIER (ouv. cité, p. 95), seuls trois vénérables de loges refusèrent de prêter leur concours à cette entreprise de renseignements. Et comme le souligne François BEDARIDA, «L'armée et la République : les opinions des officiers français en 1876-1878 ", dans Revue historique, tome 232, juillet-septembre, 1964, pp. 119-164, une semblable pratique de « fichage » des officiers avait été expérimentée au début de la Troisième République, grâce à des informateurs liés à la Maçonnerie. 111.. Sur l'épisode de Châlons et les dispositions prises par Vadecard, voir François VINDÉ, ouv. cité pp. 45-46.

112.. Voir la notice que lui consacre Daniel LIGOU dans Dictionnaire de la FrancMaçonnerie, Paris, Presses Universitaires de France, 1987, p.136. Sur ses indiscrétions, voir Lucien SABAH, « Les fiches Bidegain, conséquence d'un secret », dans Politica Hermetica, $n^{\circ} 4,1990$, pp. 68-90.

113.. Sur l'attitude d'André après les révélations du Matin et du Figaro, voir Jacques CHASTENET, Histoire de la Troisième République, tome III. La République triomphante (1893-1906), Paris, Éditions Hachette, 1955, pp. 248-250. ; Daniel LIGOU, Histoire des francsmaçons en France, Toulouse, Privat, 1987, pp. 277-278 ; Pierre CHEVALLIER, ouv. cité, p. 97 ; François VINDÉ, ouv. cité, pp. 117-146.

114.. Note de Jeanvrot datée du 7 novembre 1904 et versée à son dossier personnel.

115.. Idem.

116.. Arch. dép. (Archives départementales) Maine et Loire, extrait du Journal de Maineet-Loire, à la date des 26-27 novembre 1904.

117.. Idem.

118.. Note sur papier à en-tête de la Direction du Personnel, 25 novembre 1904.

119.. Arch. dép. Maine et Loire, 1 U 20. Rapports du commissaire central d'Angers au préfet, 26 novembre et 9 décembre 1904.

120.. À Angers, l'effervescence des élites avait été d'autant plus vive que les dénonciations et la vindicte réactionnaire s'étaient focalisées sur un magistrat de la Cour, serviteur zélé de la République, qui toujours s'était signalé par son radicalisme. 121.. Christophe CHARLE, Les hauts fonctionnaires en France au XIXe siècle, Paris, Éditions Gallimard-Julliard, 1980, pp. 109-110.

122.. Rapport du premier président au Garde des Sceaux, 26 novembre 1904.

123.. Concernant la discipline du corps judiciaire, voir en particulier Jean-Jacques CLÉRÉ, « L'exercice du pouvoir disciplinaire dans la magistrature depuis les débuts du Consulat jusqu'à la loi du 30 août 1883 ", dans Juger les juges. Du Moyen-Age au conseil supérieur de la magistrature, Actes du colloque tenu à Paris les 5-6 décembre 1997, Histoire de la justice, $\mathrm{n}^{\circ} 12,2000$, pp. 115-140 et Jean-Claude FARCY, « Les poursuites disciplinaires contre les juges de paix dans la première moitié du $\mathrm{XX}^{\mathrm{e}}$ siècle », dans Histoire de la justice, $\mathrm{n}^{\circ}$ 3, 1990, pp. 31-49.

124.. Arch. Nat. 73 AP 7. Adresses de félicitations à Émile Combes envoyées par les progressistes du Maine-et-Loire.

125.. Au lendemain de l'Affaire, Jeanvrot quitta l'Anjou et rejoignit Marseille où il mourut en 1911.

126.. Sur le remodelage de l'espace judiciaire, les réformes structurelles ou procédurales discutées sous la Troisième République, voir la synthèse de Frédéric CHAUVAUD, Le juge, le tribun et le comptable. Histoire de l'organisation judiciaire entre les pouvoirs, les savoirs et les discours (1789-1930), Paris, Éditions Anthropos, 1995, 413 p et du même auteur « L'insaisissable modèle... », art. cité, pp. 326-336. 
127.. Arch. nat.. BB6II. 956 3383. Recommandation du sénateur Leporché pour l'obtention de la Légion d'Honneur, 22 juin 1893.

128.. Proposition par le procureur général d'Angers pour le tableau d'avancement, 21 octobre 1895.

129.. Observations du procureur général d'Angers sur la notice individuelle de Jeanvrot, 4 juin 1892.

130.. Voir Christophe CHARLE, Histoire sociale de la France au XIX ${ }^{e}$ siècle, Paris, Éditions du Seuil, 1991, pp. 193 et suiv. ; Serge BERSTEIN, Odile RUDELLE [dir.], Le Modèle républicain, Paris, Presses universitaires de France, 1992, 431 p. ; Sylvie GUILLAUME, ouv. cité.

\section{RÉSUMÉS}

Jeune avocat stagiaire devenu magistrat à la faveur de la révolution de 1870, Victor Jeanvrot offre l'itinéraire d'un enfant de la République dont la force des convictions s'inscrit dans le rejet d'un Second Empire finissant et dans l'opposition à un milieu familial réactionnaire. Ses prises de positions dans le prétoire ou au cœur de l'espace public, ses écrits comme ses initiatives extrajudiciaires témoignent d'un radicalisme précoce et d'une audace réformatrice peu répandue dans un corps judiciaire enclin à la réserve. Serviteur de la loi mais aussi soldat du régime républicain, le conseiller angevin investi dans de nombreux réseaux professionnels, maçonniques et politiques, fut le promoteur du premier Congrès de la réforme judiciaire et l'inlassable artisan d'une refonte de la législation et des institutions. Ne refusant aucun combat pour être de ceux qui allaient enraciner la République, ce magistrat pourfendeur du cléricalisme, allait se compromettre dans l'Affaire des fiches et être contraint au repli dans la sphère privée. Derrière cette trajectoire singulière se dessinent les évolutions politiques et professionnelles qui traversent la société judiciaire de cette fin de siècle et s'affirme l'ascension des «nouvelles couches » à l'heure de la défense républicaine.

Justice, Politic and Freemasonery during the third Republic: an Associate Justice on the Cour d'Appel d'Angers, Victor Jeanvrot. Thanks to the 1870 revolution, Victor Jeanvrot still young trainee barister managed to become magistrate. He provides the itinerary of a Republic's child whose convictions fits in with the repulsion of the dieing Second Empire and the strong opposition to his reactionary background. His positions in Court or in public, his writings as well as his extra-judicial initiatives testify to his precocious radicalism and a reforming daring not common in the judicial corps. Servant of the law but also soldier of the republican system, this Angevin Associate Justice who was well introduced in professional, masonic and political networks, was the promoter of the first Judicial Reform Congress and the tireless architect of change in legislation and in the institutions. Turning down no challenge in order to be among the builders of the Republic, this strong opponent of the cléricalisme, was to compromise himself in the Affaire des fiches and was compelled to withdraw from public life into private sphere. Behind the straight line career of this civil servant, we can witness the political and professional developments that went through the judicial society at the end of the $19^{\text {th }}$ century, and assert the rise of the "nouvelles couches" at the time of Défense républicaine. 
AUTEUR

\section{VINCENT BERNAUDEAU}

Doctorant en histoire contemporaine HIRES. Centre d'Histoire des Régulations et des Politiques Sociales. Université d'Angers. 